\title{
Popularizing linguistic relativity
}

\author{
Spiros A. Moschonas ${ }^{\mathbf{A} \mathbb{R}^{0} 8 \text { * }}$ \\ Faculty of Communication and Media Studies, National and Kapodistrian University of Athens, \\ 1 Sofocleous Str., 10559 Athens, Greece
}

\begin{abstract}
Article info
History:

Received December 5, 2019

Accepted May 4, 2020

Published June 10, 2020

Key words:

linguistic anthropology

psycholinguistics

ethnolinguistics

history of language

Abstract

This paper distinguishes three phases in the popularization of linguistic relativity: the phase initiated by Benjamin Lee Whorf himself; a second phase during which linguistic relativity was formulated and tested as a research hypothesis; and the current phase during which language-relativistic assumptions have penetrated the mass media. To diagnose the spread of relativistic assumptions, 560 articles in both English and Greek print and electronic media were considered. The articles were published over the period 2010-2019. They fall, roughly, into eighteen categories. Some of the articles report explicitly on linguistic relativity research, while others presuppose language-relativistic ideas in handling issues as disparate as the effectiveness of managerial discourse, the appropriateness of political correctness, or the possibility of communicating with aliens. The large number of article categories as well as the tacit assumption of linguistic relativity in a growing number of articles are indicators of how popular linguistic relativity has become in folk-linguistic discourse.
\end{abstract}

\section{Introductory remarks}

"Whorf's name has shared the fate of those of many physicians who first propose a differential diagnosis, in that the condition or 'disease' he diagnosed now bears his name, Whorfianism". Thus spoke Silverstein (2000, p. 85).

The sole aim of this essay is to offer an estimate of how widespread the disease is. My diagnosis will not be of the disease but of its spread, the measure of which I sought in mediatic texts that report on linguistic issues that bear either the imprint or the presuppositions of linguistic relativity. Seeking the presuppositions of some notion or idea in texts about it or presupposing it, is - it should be admitted-a partly circular procedure. Even so, it does not prevent one from finding what one is looking for-which can be quite rewarding. The merits of the texts mined will be discussed below.

One cannot diagnose the popularity of an idea, it should be objected, unless the idea is defined in advance with certain "scientific" rigor. Indeed, a definition of linguistic relativity that would enable one, anyone, to look for its many facets in a corpus of texts such as the ones considered here is necessary. But to this purpose an operational definition or an intuitive guide to help the researcher sort out a corpus of texts would suffice. To try to define precisely the notion of relativity is a trap to be avoided. The idea of relativity itself is moldable, undergoing transformation as we speak. At some stage of its dissemination, it hardened, it simplified itself; it became stereotypical, schematic, more portable. This, I will claim, was Phase 2 in a continuing process of popularizing linguistic relativity. From the perspective of Phase 3 (the phase we are probably in), that phase (Phase 2), became known for the following simplification: linguistic relativityor linguistic relativity per se-is the idea that each language expresses a different worldview; attached to it, is the twin idea that language determines thought-linguistic determinism. This is still how linguistic relativity is presented in introductory textbooks (e.g., Lyons, 1981, p. 303-317; Fromkin, Rodman \& Hyams, 2011, p. 310-315; Baker \& Hengeveld, 2012, p. 354-357).

\footnotetext{
^Email address: smoschon@media.uoa.gr.
} 
There is an intentional ambiguity in the phrase "popularizing linguistic relativity". Linguistic relativity, originally, was not a notion to be popularized; rather, it was a popularizing notion. The most famous popularizer of whatever relativity stood for was Benjamin Lee Whorf. Many of Whorf's influential texts in his received and most accessible ouevre (Whorf, 1956) are written with the aim of popularizing, addressed as they are to a wider public, not just to the narrow circle of fellow linguists, anthropologists, Boasians (Darnell, 2001; 2006). Whorf was not the man who conceived of the idea of "relativity"it is there, explicitly, in Sapir, Whorf's teacher (hence the "Sapir-Whorf hypothesis"), and it should be counted among Boas's, Sapir's teacher, methodological principles (A language should be described on its own terms).

In modern linguistics, Saussure's "arbitrariness of the sign" (or rather its "relative arbitrariness") could very well be an alternative term for "linguistic relativity"; cf. Benveniste (1939, p. 50-51) on the "pensée historique et relativiste de la fin du xix $x^{e}$ siècle", "the historicist and relativist thought of the end of the nineteenth century", which, supposedly influenced Saussure. ${ }^{1}$ Indeed, French Enlightenment and German romanticism were imbued with notions of linguistic relativity (language's origins, a language's "spirit", a language's "climate"). Even the inhospitable to relativism Middle Ages aspired to the idea that language can be used to convert infidels or shape a society's moral canon. ${ }^{2}$ Relativity did not originate with Whorf.

\section{Three phases in popularizing linguistic relativity}

Relativity did not originate with Whorf, but he was the one to baptize "it"; and he also theorized about it. He coined a term for the general public, branded after the then becoming-popular notion of relativity in physics. I am not sure this was a wise choice, to have the highly contested results of linguistic speculation perennially compared to what had already been established as fact in a hard science, physics.

What exactly was the "it" that linguistic relativity aimed at popularizing has never become clear. After the publication of Whorf (1956), linguistic relativity (henceforth LR) became a notion to be popularized. Let us say that this was phase 2 in LR's popularizing, and that it followed Whorf's phase 1 . Phase 1 originated within anthropological linguistics, phase 2 started from within psycholinguistics. According to Pavlenko (2014, p. 14) what came to be known as "the Sapir-Whorf hypothesis" (the twin ideas of linguistic relativity per se and linguistic determinism) should better be baptized "the Brown-Lenneberg hypothesis" (see, e.g., Brown \& Lenneberg, 1954). ${ }^{3}$ It was during this second phase of its popularization that LR was solidified into the all-too-familiar twin notions of linguistic relativity proper and linguistic determinism; and a methodology started developing—-mostly experimental—for testing LR as a research

\footnotetext{
${ }^{1}$ The closest Saussure gets to fomulating a principle of linguistic relativity is in his Écrits de linguistique générale: "Is is not thought that creates the sign, but the sign that fundamentally guides thought" (Saussure, 2006, p. 27-28, 'fundamentally' translating 'primordialement'). But, given Saussure's preoccupation with "l'essence double du langage”, it is doubtful whether this formulation should be taken to mean whatever the later notion of linguistic relativity is taken to imply. As to Herderian versions of relativity: Saussure opposed the view that a language "characterizes the mental type of the social group that speaks it" or "the psychological character of a nation" (Saussure, 1995, p. 312); and he warned against the tendency to imagine that the "genius" of a race had any determinate effects on language (p. 317). He also warned against the "reasonable" hypothesis that environment and climate affect language (p. 203).

${ }^{2}$ For historical accounts see Miller (1968); Koerner (1992; 2002, p. 39-62); Penn (1992); Joseph (1996); Elffers (1996); Stam (1980); Darnell (2001, ch. 5; 2006); Leavitt (2011) - but also Lee (1996). There seem to be two schools: some historians trace the origins of Whorfian relativity in German romanticism; others, restricting themselves to the "immediate sources" of Boasian anthropology, refuse to do so, and have to explain why. Thus, both schools take the Humboldtian/Herderian relativism as their frame of reference. A full historical account of LR's evolution, starting perhaps with the Sophists, does not exist. Bock's (2003, p. 463) reasonable suggestion that Aristotle's Rhetoric III is an early predecessor to LR is being dismissed by Koerner (2002, p. 41), who thinks has found his favorite precursor in Leibniz.

${ }^{3}$ The anthropologist Harry Hoijer (1954) was perhaps the one who first launched the term "the Sapir-Whorf hypothesis"; cf. Koerner (2000). John B. Carroll, Whorf's editor, employs the term "the linguistics Weltanschauung problem” in his The Study of Language (Carroll, 1953, p. 43) and "the Sapir-Whorf hypothesis" in his Introduction to Whorf's writings (Whorf, 1956, p. 27).
} 
hypothesis, despite the fact (I take it to be a fact) that LR was meant to be a cover term for a set of linguistic observations rather than a hypothesis to be tested.

Roger Brown (1958, p. 229-231) undertook to explain the notion of linguistic relativity against the backdrop of a view he opposed, which he thought was prevalent at the time of his writing-or so he pretended: objectivism. What is "popularly believed" about language and thought, said Brown, is that message and code are separate: most people, especially through the learning of foreign languages, come to aspire to "objectivism": some kind of antonym to relativity. Objectivism was, according to Brown, the "popular view", perhaps because it needed not defend itself. Relativity was the underdog. It should be noted that, occasionally, Whorf also adopted the same rhetoric (cf. Schultz, 1990) and wrote as if he was defending relativity against the prejudices of the dominant frame of mind in his milieu-the Standard Average European mind, perhaps.

Can we talk of a third phase in the popularizing of LR, following the popularizing by Whorf and the popularizings of the popularizing by the Browns and Lennenbergs? Are we now in a new era of "popular Whorfianism"? My conviction is that, indeed, LR goes through a new phase of popularization. But before I provide evidence for this claim, let us take note of what the experts on this subject, i.e. the journalists of linguistics, have to say.

McWhorter in his polemical and disputable The Language Hoax forces a distinction between academic and popular Whorfianism. For him, Whorfianism is the hypothesis or, rather, the maxim that "language shapes thought" (McWhorter, 2014, ch. 3). One may assume that the verb of the phrase 'language shapes thought' he understands it in in all its cognates: 'controls,' 'affects', 'influences, 'determines', 'constrains,' 'channels. "Popular Whorfianism [...] just isn't true. Academic Neo-Whorfianism is-make no mistake", says McWhorter, the academic (p. 48). For McWhorter, then, academic Whorfianism is just true and popular Whorfianism is just false. Very convenient, indeed: relativity within science is true; popular relativity outside science, but originating from it, is not. But there is no popular Whorfianism so different from academic Whorfianism, simply judging by the fact that there have been, starting with Whorf, so many professionals who took to popularizing their insights into LR. In the history of linguistic ideas, LR is perhaps the only ideological constellation with so blurred a distinction between folk and professional linguistics. The publications in category (LR2) below exemplify how blurred the distinction is between linguistics and folk linguistics on the subject of LR.

But let us try to follow McWhorter's line of thought and ask: Who are the forgers of scientific relativity in popular discourse? For McWhorter, popular Whorfianism is the result of "popular books such as Daniel Everett's Don't Sleep, There Are Snakes (2008), Deutscher's Through the Language Glass (2010), well-publicized studies by Stanford psychologist Lera Boroditsky, and other works [that] have established a Whorfian meme in public discussion" (McWhorter, 2014, p. xiv). But of those cited by McWhorter, Everett is, I would think, a cultural relativist: for him, languages reflect cultures-which is not exactly the same dogma as 'languages constrain thought'. Deutscher is also a fervent supporter of cultural relativism and self-proclaimed historian of linguistics; he came up with the following appraisal of Whorf: "the most notorious of the con men, Benjamin Lee Whorf, who seduced a whole generation into believing, without a shred of evidence, that American Indian languages lead their speakers to an entirely different conception of reality from ours" (Deutscher, 2010, p. 21). On the basis of this statement alone, I gather, he should be expelled from the club of Whorfianists but also perhaps from the ranks of academics. Boroditsky is a popularizer of others' and her own experimental work on LR, and she is very good at that-McWhorter ought to count her among the academic Whorfians. Incidentally, from today's perspective one should also count McWhorter's book among those that helped establish the 'Whorfian meme', something that McWhorter himself could not have foreseen.

McWhorter is not an opponent of relativity, but Pinker, who is, in The Stuff of Thought (2007) had also observed that the Sapir-Whorf hypothesis "through the early 1970s [...] had penetrated the popular consciousness" and that "recently it has been resurrected" under the label of neo-Whorfianism: "several recent studies purporting to show that language determines thought have been widely reported in the 
media" (Pinker, 2007, p. 128, 124-125). Notice that both McWhorter and Pinker, friend and foe, think of popular Whorfianism as the "dominant ideology". So, "objectivism" has ceased to be dominant; perhaps, Browns and Lennenbergs should be given proper credit for this shift in ideological orientation.

If phase 1 was Whorf's and phase 2 of Whorfians, phase 3 might very well be of "neo-Whorfians", one is tempted to say. But who are those "neo-Whorfians"? There are now important reappraisals of Whorf's work and reformulations of his whole "theory complex" (Silverstein, 1985, 2000; Mertz \& Parmentier, 1985; Hill \& Mannheim, 1992; Lee, 1996; Leavitt, 2011; Pavlenko, 2014). Such reappraisals had had a rather deconstructive effect, de-arranging the way linguists have understood linguistic relativity. It is not the reading of Whorf by those authors that is being popularized in the media-and it could not be, because it is difficult to follow. Perhaps the term "neo-Whorfians" applies to those researchers who have tried to redesign the experimental techniques and apply them to new domains (Lucy, 1992a,b; Gumperz \& Levinson, 1996; Pütz \& Verspoor, 2000; Niemeier \& Dirven, 2000; Levinson, 2003; for critical reviews see Björk, 2008; Everett, 2013). But not much of this work was ever reported in the media; and not many of these researchers claim the name "neo-Whorfian" for themselves. If the term "neo-Whorfians" is to be restricted to those few experimenters (such as, perhaps, Lera Boroditsky, Panos Athanasopoulos, and quite a few others), who advertize their work in the media, so be it. Category (LR2) below contains the mediatic texts that bear testimony to recent attempts by linguists and associates to verify the "linguistic relativity hypothesis" experimentally or through case studies of languages' lexicons and grammars. But applying the term "neo-Whorfian" only to those researchers whose work reaches the media sounds like a false accusation. Popularizing one's work is a legitimate task, even perhaps an obligation of the professional linguist (Labov, 1982, p. 173); and why not seek some publicity while at the same time enlightening the public? So that, perhaps, it is not "neo-Whorfians" to be held responsible for spreading the term "linguistic relativity" beyond recognition but rather popularizing accounts such as Pinker's (2007), Deutscher's (2010), and McWhorter's (2014).

As I wish to show, the characteristic of this third phase of popularizing LR is not the persistence of relativity and determinism as guiding principles. Rather, it is the spreading beyond recognition of the notion of LR in additional domains, its becoming presuppositional, its functioning as a covert rather than an overt principle that guides the whole range of publications in categories (LRI) to (LR I 8) below. Category (LRI) covers general reports on relativity and (LR2) covers reports on specific experiments and case studies. But LR can also be recognized in other types of publications, where it is not explicitly mentioned. At this stage of its expansion, the third stage in the popularization of LR, the explaining of the idea is done not against some kind of objectivism, as Brown had it, but rather on the ground of its previous popularizations. LR is becoming the "dominant" ideology for certain linguistic issues-and that is what friends and foes, McWhorters and Pinkers, rightly foresaw.

\section{A corpus of mediatic texts}

The precedent for the study described in this section is Mertz (1982), who sought a "folk theory" of LR in a corpus of United States law documents. My corpus consists of publications in the print and/or electronic English and Greek media (henceforth: publications) that are either thematically, metalinguistically, about linguistic relativity or presuppose it for covering some related linguistic issue. (I have already acknowledged the circularity of this criterion for constructing a corpus.) The total number of publications about or around linguistic relativity considered is 570, the earliest is dated August 26, 2010 and the latest January 7,2019 . All 570 publications were selected out of a bigger corpus about several linguistic issues, consisting of: 2,651 publications from the early 2010s until 31.12.2015 (with no systematic archiving), 5,049 in 2016 (when systematic archiving started), 2,476 in 2017, 2,666 in 2018, and 67 (already) in 2019. Zeal might have been a factor for the significantly larger number of publications in 2016. Republishings were retained in both corpora. Interestingly enough, all the Greek texts in the corpus are republishings (translations or paraphrases with or without permission) from English news media. 
For building the corpus over the last few years I have used a few news app(lication)s: Feedly, Microsoft News, Google News, News360, Flipboard. All draw mainly from American media; several combinations of keywords, feeds, or predefined "interests" in those apps have been tried. News feeds were used for the Greek texts. But what databanks and mining criteria the apps themselves employ I am only vaguely aware. Admittedly, the construction of the corpus was beyond my control and I will not pretend otherwise. Choosing which news will be chosen for you is perhaps an informed reader's preferred way of reading the news in a digital era. But it might also be a source for misinformation, as the reader has no real control over the texts s/he is served.

For the methodological habit of constructing a smaller, thematic corpus out of a larger one, see Moschonas (2014). The percentage of publications on LR in the smaller corpus to the total number of publications on linguistic issues is $4.438561 \%$ (false precision? rounding the figure to $4.44 \%$ would make it look more suspicious). Of course, it is not clear what this figure measures, since the smaller corpus is as much the result of interest as it is of a thematic rearrangement of the larger corpus. However, to teach linguists some humility, it would be reasonable to assume that publications on or around linguistic relativity in the print and/or electronic media are only a small percentage of the publications about any linguistic issue; and publications about any linguistic issue are just a tiny percentage of publications about issues non-linguistic (cf. Moschonas, 2014, p. 398).

Publications in the media provide, to borrow a term from Nietzsche, a "medium-height" into language ideologies. One can survey the land below, without losing sight of the heights. Mediatic texts are addressed to a wider public, they are not burdened with academic technicalities, they are more commonsensical than most linguists manage to be. While addressed to the folk, they do not block the view to the higher strata of professionals who manufacture language ideologies within linguistics. But we will not be concerned here with the communicative trajectories joining linguists and journalists with a wider public.

Constructing a corpus inevitably involves certain decontextualizing of the texts, the body of which one is afterwards tempted to treat as a single text. This is a common critical fallacy. I saw that the smaller corpus contains a sufficient number of specimens as well as categories. I also saw that it contain both polemical and non-positional texts and as many texts pro as against relativity. Ideologies exist only in the plural and the ideologies of linguistic relativity, a highly contested issue, are no exception.

Borges' famous classification of animals contains the following division: "all animals included in the present classification”. My classification risks being more paradoxical; it contains all those categories of publications not included in the present classification. Namely, three of the categories presented below, (LRI S) to (LRI7), are underrepresented in the smaller corpus. First, (LRI 5): the sci-fi movie "Arrival" (2016) gave rise to several publications that undertook to popularize linguistic relativity, which is a key notion in the script (Moschonas, 2017); there are also publications about fictional alien languages (conlangs); and surveys of Xenolinguistics. Only a representative few are included in category (LR I 5). As for (LRI6)-(LRI 7): no exhaustive survey of publications about linguistic relativity could leave out the kind of hard Herderian relativism evidenced in some media, usually in relation to a "national" language. Modern Greek is a case at hand. About linguistic nationalism in Greece (LRI 6) and the monoglossic ideals behind prescriptivism in Greece and elsewhere (LR I 7), I will refer the reader to Moschonas (2004, 2009). Only a few representative publications are taken into consideration here. After Borges, one should be less apologetic for having fashioned a classification after one's own interests.

Are the categories exclusive, i.e. is there one and only one category for each publication? Conceptu-

\footnotetext{
${ }^{4}$ The phrase (Von halber Höhe aus) is from Nietzsche's "Worldly Wisdom” (The Gay Science) in W. Kaufmann's rendering: "Do not stay in the field! / Nor climb out of sight. / The best view of the world / Is from a medium height"; Nauckhoff's translation: "Stay not where the lowlands are! / Climb not into the sky! / The world looks best by far / when viewed from halfway high"; the original: "Bleib nicht auf ebnem Feld! / Steig nicht zu hoch hinaus! / Am schönsten sieht die Welt / Von halber Höhe aus".
} 
ally, the categories are interrelated, overlapping, some might even be considered subcategories of others. For example, (LR2) contains specific illustrations of linguistic relativity which exemplify the more general or theoretical surveys contained in (LRI). Managerial discourse (LR7), prescriptive discourse (LRI 6), political correctness (LR7) are also strongly connected as all the discourses in question exercise some corrective power and they all presuppose that language shapes behavior. Despite the conceptual overlappings, each publication was arbitrarily forced into a single category.

There is a total of eighteen categories. Here is the full list, with specimens and comments following:

$\begin{array}{ll}\text { (LRI) } & \text { LR exposés } \\ \text { (LR2) } & \text { LR cases } \\ \text { (LR3) } & \text { Bi-/Multi-lingualism } \\ \text { (LR4) } & \text { Threatened languages } \\ \text { (LR5) } & \text { Translation } \\ \text { (LR6) } & \text { Untranslatable words } \\ \text { (LR7) } & \text { Political correctness } \\ \text { (LR8) } & \text { Managerial discourse } \\ \text { (LR9) } & \text { Inverse determinism }\end{array}$

(LRIO) Ideological discourse

(LRII) Conceptual metaphors

(LRI2) Media-genre relativism

(LRI3) Etymological relativism

(LR I 4) Cultural relativism

(LR I 5) Nationalism

(LRI6) Prescriptivism

(LRI7) Talking to Aliens

(LRI8) References en passant

(LRI). LR exposés. Articles in (LRI) are popularizations of academic neo-Whorfian research, overviews, appraisals.

Let's see a few examples. Grammar Girl's "Does your language influence how you think" (Quick and Dirty Tips Nov. 22, 2018; also in Scientific American Nov. 30, 2018) is a "balanced" account of LR; it defends it against counterarguments, it presents some oft-discussed studies (about color names, spatial relations, gendered languages), and concedes to this view:

ongoing research has found areas here and there, where some evidence does suggest that the inherent features of your language can change the way you think-but in small ways.

On the other hand, "The Sapir-Whorf Hypothesis" by Richard Nordquist, ThoughtCo. Oct. 27, 2017 (updated Nov. 1, 2018), a text written by a "Professor of English and Rhetoric for 35 years", is clearly hostile to LR. It contains definitions, a historical account, a critique and lots of inaccuracies. Both texts are typical members of the category (LRI).

It is not clear whom these texts are addressed to. They can be compared to an encyclopedia's entries. How accurate LR is presented in such articles is also irrelevant. The much less authoritative and oversimplistic "A mini study in metaphysics: How language creates us", by Chris Miller, Sophomore in Communication, published in the students' newspaper The University of Dayton Flyer News Feb. 25, 2017 also belongs to (LRI). From the perspective of popularization, both types of text are interesting, the erudite and the naive, the latter perhaps more so than the former.

I gave examples of texts whose authors are reluctant to accept "the linguistic relativity hypothesis". Guy Deutscher ("Does your language shape how you think?", The New York Times Magazine Aug. 26, 2010) is much less equivocal: "The habits of mind that our culture has instilled in us from infancy shape our orientation to the world and our emotional responses to the objects we encounter". As an indication of LR's popularity, it should be mentioned that the non-presuppositional title ("Does your language influence how you think?", ibid.) is less common compared to the presuppositional ones: "How the language we speak affects the way we think" (by Antonio Benítez-Burraco, Psychology Today Feb. 2, 2017); "How the language you speak influences the way you think" (by Neel Burton, Psychology Today Aug. 8, 2018); "How language shapes our perception of reality" (by Vivian Gang, Fast Company July 28, 2018); "How has language shaped who you are" (by Esmeralda Bermudez, Los Angeles Times June 14, 2018); "How has language shaped your world" (Los Angeles Times July 8, 2018). 
The difference of texts in (LRI) from those in category (LR2) is that the former do not concentrate on specific cases but rather they survey the available evidence supporting a more general claim: LR. However, there seems to be a common inventory of cases from which these overviews draw. For example, this is how Lera Borodinsky's summarizes the research findings on "how language shapes the way we think" in her Ted talk (Ted Nov. 2017; cf. Boroditsky, 2003):

Now, I've given you a few examples of how language can profoundly shape the way we think, and it does so in a variety of ways. So language can have big effects, like we saw with space and time, where people can lay out space and time in completely different coordinate frames from each other. Language can also have really deep effects-that's what we saw with the case of number. Having count words in your language, having number words, opens up the whole world of mathematics. Of course, if you don't count, you can't do algebra, you can't do any of the things that would be required to build a room like this or make this broadcast, right? This little trick of number words gives you a stepping stone into a whole cognitive realm.

Language can also have really early effects, what we saw in the case of color. These are really simple, basic, perceptual decisions. We make thousands of them all the time, and yet, language is getting in there and fussing even with these tiny little perceptual decisions that we make.

Language can have really broad effects. So the case of grammatical gender may be a little silly, but at the same time, grammatical gender applies to all nouns. That means language can shape how you're thinking about anything that can be named by a noun. That's a lot of stuff.

And finally, I gave you an example of how language can shape things that have personal weight to us-ideas like blame and punishment or eyewitness memory. These are important things in our daily lives.

Chris Weller, a "senior innovation reporter", reports on the "most fascinating findings" from Boroditsky's talk in a more colorful way: "time can flow in all different directions"; "inanimate objects take on human descriptions of gender"; "what you call a color determines how much you notice it"; "grammatical structures can lead people to focus on different details of a crime scene" ("A leading cognitive scientist reveals how language shapes your perception of gender, color, and justice", Business Insider Nov. 7 2017). It is my impression that Boroditsky's talk has been quite well-received. It helps bridge texts in category (LRI) with those in the next category.

(LR2). LR cases. Articles in this category tend to be more specific. They report on particular experiments or case studies. Some of them are research advertisements, originating from professionals: a press release is issued and the reporter reports on it; or the researcher himself publishes a short piece on his or her own work.

"Your language influences your color perception, says a new study", says a report (Olivia Goldhill, "The language you speak changes the colors you see", Quartz Nov. 7, 2018, with reference to Maier \& Rahman, 2018). "Language controls what colors you can and can't see, or does it?", reports another article (by Scotty Hendricks, Big Think Jan. 10, 2017, with reference to Franklin et al., 2008). Common are the reports on relativity effects on the perception of color, space, time, gender. Issues of morality are not left untouched, e.g. lying in a second language is considered easier or more difficult depending on the line of research one reports upon ("Lying in a foreign language is easier", Science Daily July 19, 2018, with reference to Suchotzki \& Gamer, 2018; compare with Jaime Fraze, "You cannot tell a lie - in your nonnative language", From the Grapevine Aug. 31, 2018, with reference to Bereby-Meyer et al., 2018). There are also reports on other capacities found to be affected by language: "Do speakers of different languages hear music differently?” (MedicalXpress Feb. 24, 2016, with reference to Langus et al., 2016).

Not all reports are on experimental research. In (LR2) also belong case studies of particular lexical fields, grammatical phenomena, or functional and pragmatic characteristics of languages. Some topics 
seem to be recurring in the media. Despite the demythologizing by Pullum (1991), the "Eskimo words for snow" is still a thing: see, e.g., David Robson, "There really are 50 Eskimo words for 'snow" (The Washington Post Jan. 14, 2013); and, guess what, "Researchers say Scots have the most words for snow" (reports Jill Lawless in the Toronto Sun Sept. 24, 2015), precisely 421 words (Nick Winchester, "Researchers for New Scottish Thesaurus Find 421 Words for Snow", Newsweek Sept. 24, 2015).

The case studies range from the dead serious to the ludicrous. The "Whorfian economics"-type of studies, for example, should, as a whole, be considered to be misapplications of the principle of relativity, as they try to correlate the unrelatable. But it is such cases that attract attention in the literature and the media (e.g., "The language you speak may affect your ability to get rich", by Kathleen Elkins, Business Insider Aug. 3, 2015, with reference to Keith Chen, "Could your language affect your ability to save money?", Ted June 2012; see also the relevant discussion in the Language Log, with Chen's response here). The following are also about studies in "Whorfian economics" that seek to correlate a linguistic feature, such as "futurity", with the ability to make decisions and/or to save money, on a national or global level: "Language shapes people's time perspective and support for future-oriented policies" (by Melissa Heeke, American Journal of Political Science Jan. 25, 2017); "David Mas Masumoto: How our use of language can frame our future" (The Fresno Bee Feb. 27, 2016). Whorf's original studies on the temporal system of Hopi compare better with such relativistic accounts of temporal systems as reported in: "Does language alter how we perceive time" (by Panos Athanasopoulos, The Wire June 16, 2017, also reported in "Your perception of time may depend on the language you speak", The Sunday Times May 8, 2017, and elsewhere); "How our minds construct the past, present and future depends on our relationship with time" (by Sarah Duffy, The Conversation Jan. 3, 2018); and so on. For Whorf, the Hopi temporal system was a window into the Hopi "metaphysics"; for recent research, temporal systems are embodiments of distinct thought patterns.

It should be acknowledged that in category (LR2) there are also articles which cast doubt on particular studies that purport to have verified the linguistic relativity hypothesis with respect to this or that lexical or grammatical phenomenon. Alternatively to relativistic theories of color, for example, there are publications that place emphasis on universal constraints, e.g., "The surprising pattern behind the names of colors around the world" (Open Culture Aug. 6, 2018, with reference to Berlin \& Kay, 1999). One should also follow the relevant threads in the Language Log; these are some representative posts: Geoffrey K. Pullum, "Keith Chen, Whorfian economist" (Language Log Feb. 9, 2012); Mark Liberman, "Cultural diffusion and the Whorfian hypothesis" (Language Log Feb. 12, 2012); Keith Chen, "Whorfian economics" (Language Log Feb. 21, 2012); Mark Liberman, "Candidate for careless Whorfian nonsense of the year" (Language Log Mar. 11, 2018).

As already explained, the categories (LRI) - (LRI 8) are exclusive in only a forced, arbitrary way that facilitates the classification. Overlappings between categories are to be expected. The bulk of media reports in category (LR2) is about studies purporting to show the effects upon behavior of different languages; thus publication in (LR2) are also, directly or indirectly, about bilingualism or multilingualism, the subject of our next category, (LR3).

(LR3). Bi-/Multi-lingualism. I prefer to think of the publications in this category as forming a locus, a conceptual topos (Spitzmüller, 2005, p. 271; Spitzmüller \& Warnke, 1978, p. 191) rather than as sharing a topic. Not all publications about bi/multilingualism (the topic) adopt a relativistic stance, but $\mathrm{bi} /$ multilingualism is the rich ground (locus) on which a relativistic stance can grow.

Let me explain simply by comparing two subclasses of publications within (LR3). On the one hand, there are those that promote what is called "the benefits of bi-/multi-lingualism", benefits which range from delaying dementia (Ellen Bialystok, "The health benefits of bilingualism", goop n.d.) to looking sexy (Maureen O’Hare, “Does being bilingual make you sexy?”, CNN Travel Apr. 2, 2017; cf. "Learning a new language stimulates same pleasure centres in the brain as sex and chocolate", by Priya Joshi, International Business Times Oct. 25, 2014). Not any of these publications adopt an overtly relativistic stance, although none is incompatible with it. On the other hand, there are those publications that adopt a clear relativistic 
stance with respect to bi/multilingualism, e.g. "Learning a new language changes the way you perceive reality" (by Ivan Miguel, 2uartz Nov. 29, 2017). The bilingual advantage in this case is the relativistic effect; it is a perceptual advantage, one that relates to thought or cognition. And it is the perceptual advantage, now recognized as a skill or a talent, that is promoted in several publications: e.g., "How a second language can boost the brain" (interview with Mark Antoniou, Knowable Magazine Nov. 29, 2018; cf. Antoniou, 2019); "5 ways being bilingual makes you smarter" ( $K$ Blog Sept. 25, 2017; republished as "How being bilingual makes you smarter", Grammarly Blog Nov. 26, 2018); "Multilingualism is good for your mind - and body" (by Hans Pienaar, Business Day June 12, 2018); etc. A few articles assume a similar attitude towards bi- or multi-dialectalism: "Speaking multiple dialects of the same language is good for your brain” (by Arika Okrent, Curiosity Sept. 6, 2018).

It is interesting to note that there is now a considerable number of similar publications (mostly adapt-

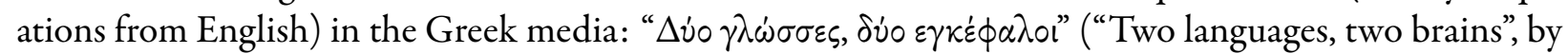

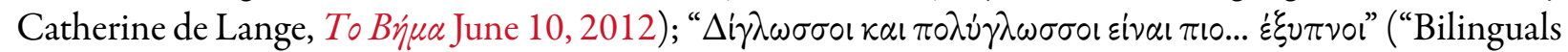

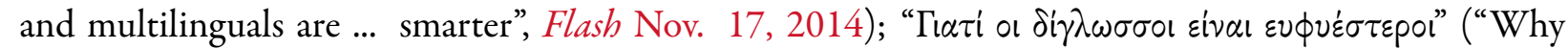

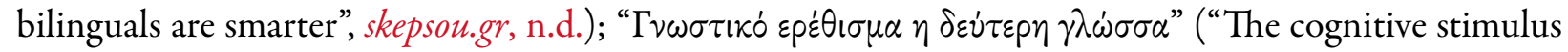

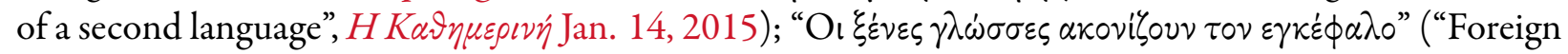

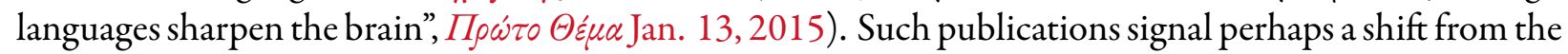
monoglossic mindset that was characteristic of the Greek media in the 1990s (Moschonas, 2001, 2004) to a more liberal attitude towards bi/multilingualism. One should realize that bi/multilingualism was not always and not everywhere so highly valued as it is now. Perhaps this re-evaluation of multilingualism now casts its shadow on media that have traditionally favored a monoglossic ideology.

If language is the cause and mind is the effect, one can now deduce the additive advantage of bilingualism, summarized in the maxim: "two languages two minds" (the expression is borrowed from Athanasopoulos et al., 2015; cf. Panos Athanasopoulos, "How the language you speak changes your view of the world" The Conversation Apr. 27, 2015). In the article just cited, the view of a professional is encapsulated; for the folk-linguistic perspective, compare, e.g., with the narrative of some Simone Imurah, "A Polyglot Mind" (The Writing Cooperative Apr. 13, 2018), who claims to be a polyglot for whom "'Good morning! Thank you! Excuse me and I am sorry!' [...] are the magic words in any language”; we are all polyglots, then.

The notion of a "bilingual mind" or a "bilingual brain" is, of course, the topic of interesting scientific research (Javier, 2007; Hernandez, 2013; Costa, 2019) that has served as the basis for lucid re-evaluations of Whorf's ideas (Pavlenko, 2014); not much of this research, I am afraid, is reported in the media. Research that questions the advantages of bilingualism is also disregarded. The English media are overwhelmingly in favor of bi/multilingualism—and of multilingualism more than bilingualism.

(LR4). Threatened languages. This is again a locus rather than a thematic category, in the sense that the articles in it are not dedicated to LR, yet they seem to presuppose it and the probability is high that some mention of LR or a LR-related concept will surface in most of the articles. The mentions tend to be of the following type: "The loss of native American languages affects our understanding of the natural world”(by Rosalyn R. Lapier, Salon Oct. 10, 2018); "When languages die, we lose a part of who we are" (The Conversation Dec. 9, 2015); "When a language dies, a unique perspective dies with it" (stated in "A way of understanding: When a language dies, a world dies with it", The Register-Guard Dec. 31, 2017); etc. "The-loss-of-a-language = Loss-of-a-worldview" motif seems to be a presupposition of some academic work as well. As stated by David Harrison in the documentary “The Linguists" (2008): "When a language is endangered we worry that some kind of unique way of seeing the world could be lost".

The articles in category (LR4) are not only about threatened or dying languages, but also about dead languages such as Latin or Ancient Greek, which are supposed to embody a unique, influential, lasting perspective into the world's civilization; e.g., this is how Andrea Marcolongo advertises her best-seller La lingua geniale: 9 ragioni per amare il greco (2017): "il greco antico era un modo di vedere il mondo" 
(Editori Laterza); the translation of the book into Modern Greek is publicized in the exact same way: " $\eta$

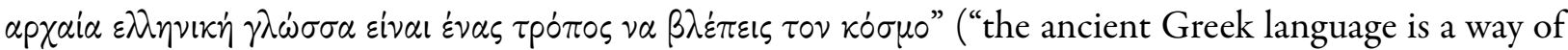
viewing the world", $\beta$ i $\beta \lambda$ เonet); compare with the more analytic description in English: "Every language captures the world in a unique way: the stranger the vision, the more interesting the language. This is the idea behind Andrea Marcolongo's captivating book on the mysteries of ancient Greek" (Editori Laterza). For an article that compares more closely with those in category (LR2), see the following on the color vocabulary of the Greeks: "The sea was never blue: The Greek color experience was made of movement and shimmer. Can we ever glimpse what they saw when gazing out to sea?" (by Maria Michela Sassi, Aeon July 31, 2017).

(LR5). Translation. This is again a locus rather than a thematic category. Statements of commitment to LR are not absent from the publications that are included under this label: "Translation gies us a vital windae intae ither warlds", as the ironist Ishbel McFarlane puts it in a re-invented Scottish (The National Nov. 1, 2018). LR-related notions and attitudes also surface in at least some of the publications about translation, because translation illustrates issues of bilingualism, contact, mediation; also because it is a mechanism that can portray relativity (think of Whorf's own "mechanism of glossing", through what he called "lexations"; cf. Silverstein, 2000, p. 92-93). Here is an excerpt from an interview with the translator Daisy Rockwell (Language Chat Nov. 16, 2018), exemplifying the usual difficulties translators face while also illustrating the process of calibrating one language through another:

Kinship terms are hands down the most difficult aspect of translation into English from South Asian languages in my opinion. Women's writing contains way more of these terms than men's writing, simply because there is more action inside the house than outside, generally. With these I try my best to come up with English equivalents, but also include some original terms so I won't be accused of over-translation. The problem with the kinship terms of course, is not only are they very elaborate, but they are all context-centric, so one person's devar is another person's bhai sahib, is another's chacha ji, etc.

I consider the above excerpt to be typical of a series of publications about translation: it focuses on a local linguistic issue (kinship terms) which arises in translation; it places emphasis on rendering the forms rather than explicating their conceptual or cultural substratum; and aims at resolving the issue, one way or another, in a target language. Contrary to the common view, translation is not a counter-argument to LR; it can also be an accomplice of LR. Translation is a means for "calibrating" (Whorf, 1956, p. 214) languages against each other.

As it was expected, (LR5) contains several publications of the lost-in-translation type. Indeed, we have to postulate a special subcategory: untranslatable words.

(LR6). Untranslatable words. Unlike most publications in (LR5), where the opinion of the professionals matters, the ones in this subcategory are mostly curiosities addressed to a wider public. "Saudade" (Portuguese) and "filotimo" (Modern Greek) are two examples of "untranslatable" words. There are plenty dictionary-like publications: "20 untranslatable words in different languages that describe emotions \& situations" (Learning Mind Nov. 3, 2018); "19 amazing untranslatable words" (The Telegraph June 4, 2018); etc. By "untranslatable words" it is, of course, meant "untranslatable into English". The untranslatable words are always presented with their translations or paraphrases: "Untranslatable words (and their translations)" (by David Shariatmadari, The Guardian Aug. 21, 2014). The untranslatable words are mystified; it is insinuated that their being untranslatable implies something deeper, albeit it is not clear what. This mist surrounding "untranslatables" presents, of course, a mystery to the layperson as much as to the professional explorer of concepts: cf. Cassin (2004). Often, it is assumed that untranslatable words reveal something about the people who speak the language, a national characteristic (as it is the case with 
"filotimo": see "The Greek word that can't be translated", by Stav. Dimotropoulos, BBC Travel June 7 ,

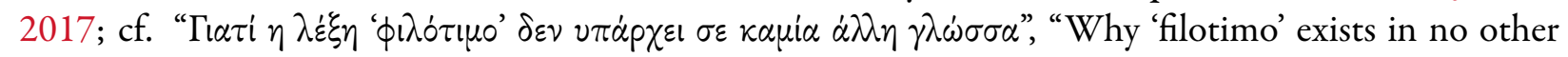
language", Newsbomb Oct. 16, 2015).

I will look at the next five categories, (LR7) through (LRI I), as forming a coherent group. I will first explicate the interrelationships between the categories in this group and then I will give a few examples from each category in the listings that follow.

Most publications in the group (LR7)-(LRI I) deal with a performative aspect of LR-and also, at the same time, an ideological one: they are about manifestations of LR for which J.L. Austin's famous dictum "saying is doing" seems to hold valid; and, at the same time, they reveal the presuppositions, stances, or ideologies which lay hidden in discourse. Take, for example, political correctness (LR7). As a linguistic practice, political correctness exemplifies both dogmas of phase-2 relativity: determinism and relativity proper. Political correctness aspires to the ideal that one can be helped in shaping one's thoughts about race, age, gender, sex (or what not) through the appropriate use of language. There is thus a strong belief in determinism ("language shapes thought") exemplified in the very corrective practice of political correctness; which, at the same time, is revelatory of the values, stances, attitudes, ideologies, etc. which, presumably, are encrypted in the language stigmatized as inappropriate. Through its unequivocal acceptance of determinism, political correctness is associated with types of discourse whose aim is persuasion, such as marketing or managerial discourse in business communication, in neuroprogramming, but also in classical rhetoric (with its full realm of applications); the relevant publications about these issues belong to the next category (LR8). (LR7) and (LR8) share a managerial conception of discourse. Now, if this type of discourse is to take effect and "determine" the thought of the people trapped in it, then a kind of inverse determinism is also possible, by means of which language is turned into the symptom of the thought that has been inflicted upon it; for example, a way of expressing oneself might be indicative of racism and/or other stances, or of depression and/or other traits of the person speaking. The publications which treat language as a symptom of a more general frame of mind belong to category (LR9). The relation between the three categories is now clear: if determinism is possible (LR7-LR8), then indexicality is also possible (LR9): if language shapes thought, then language is a symptom of thought. It would be more appropriate to speak of modes or frames of thoughts or frames of mind rather than simple thoughts in these cases. Such modes of thought are crafted into the mould of ideologies (LRIO) and they are revealed through the analysis of "conceptual metaphors" (LR I I), which are but the symptoms of modes of thought (Lakoff \& Johnson, 1980). Let us summarize: what categories (LR7)-(LRI I) have in common is the idea that language can be managed in ways that constraint our thoughts (determinism) and that in languages are embedded or ingrained certain modes of thought which are revealed by the analysis of "concepts we live by" (relativism proper). Simply put, relativity is seen as the effect of determinism.

Having provided this overview, we can now list a few examples from each category.

(LR7). Political correctness. Concerning racism, this is, I think, a representative publication with a self-explanatory title "Warning: Why using the term 'coloured' is offensive" (by Amelia Butterly, $B B C$ News, Jan 28, 2015). It should be pointed out however that the targets of political correctness vary depending on the stance or ideology of the persons involved in the practice of stigmatizing language. One should compare the following two publications: first, "Ariz[ona] college denounces 'Whiteness'-fueled hate speech" (by Kaila White, USA Today Apr. 30, 2015) is a piece that reports on the reactions of "white nationalists and "hate preachers" who responded to a course on the "problem of whiteness" taught by Lee Bebout at Arizona State University. But then this is another piece in the same journal at about the same period of time: "How do we find the language to fight racism?" (by Jessica Masulli Reyes, USA Today Dec. 6, 2015); written on the occasion of a black teen being gunned down by a police officer, the article examines the merits of avoiding the "racially charged term 'white supremacist". Notice, in passing, that articles in this category are not necessarily politically correct (although most are); rather, they are about 
political correctness.

Other publications in category (LR7), with a clear relativistic leaning, partially overlapping with publications in (LR2), are about sexism: e.g., "How gender stereotypes are built into Mandarin" (The Economist Sept. 6, 2018); "Feminists" target German language as sexist" (by Austin Davis, USA Today July 9 , 2018); “Is the German language sexist?” (German Language Blog Aug. 29, 2018). There are also several publications about gender-neutral pronouns, e.g. "Gender neutral pronouns: What they are \& how to use them" (by Caroline Forsey, HubSpot Sept. 28, 2018). It should be pointed out that the linguist Deborah Cameron often publishes enlightening entries about sexism and linguistic discrimination in her blog "Language, A Feminist Guide", most of which fall into this category.

Certainly, racism and sexism, according to the relevant publications, are the most common targets of political correctness. They are not the only ones. Recently, PETA (People for the Ethical Treatment of Animals), an animal rights group, urged people to stop using "anti-animal phrases", such as "kill two birds with one stone" (the alternative suggested is "feed two birds with one scone") ("PETA Asking People to Stop Using 'Anti-Animal Language”, by Ashley Carter, Spectrum News - News 13 Dec. 5, 2018). The proposal was met with scorn (see, e.g., "PETA forgot to correct these anti-animal phrases", The Late Show with Stephen Colbert Dec. 6, 2018).

(LR8). Managerial discourse. Here are a few representative samples: " 5 ways language training improves employee performance" (by Melanie Rogers, ATD Nov. 29, 2018); "Language study reveals best words to use when selling products" (Science Daily Apr. 29, 2016); "Change your words, change your life"5 (by Tony Robins, Thrive Global Mar. 17, 2017); "How a simple verbal shift could change your life” (original title: "Change a word, change your life", by Mel Schwartz L.C.S.W., Psychology Today Sept. 5, 2018); etc.

The mediatic texts on managerial discourse are not about business communication only; as the last two examples show, some appear under the tag 'self-improvement'. Presentations (or applications) of NLP also fall into this category: "Make positive life changes with NLP” (Excellence Assured Oct. 24, 2017); "5 NLP techniques to change your life" (Sprouts Change June 30, 2017). "The power of words", "the power of positive speech", "transformational words" and similar expressions tend to recur in the mediatic texts of this category. According to Robins (op. cit.):

This is the power of what I call Transformational Vocabulary - consciously using your words to improve the quality of your life today and for the rest of your life.

And here is how Schwartz (op. cit.) explains, in his lofty philosophical style, why the use of the verb 'to be' (and other statives, one should add) restrains our possibility for change:

The thesis of an objective reality became replaced by a participatory subjective reality. This new worldview looks very warm and friendly to humans, as human participation informs reality, and we no longer see ourselves as disconnected objects. To access and benefit from this new vista of reality, we need to alter our language since the to be [verb forms] keep us stuck in $17^{\text {th }}$-century reality.

As explained already, publications in (LR8) are closely related to the ones in the next category.

(LR9). Inverse determinism. If the advocates of political correctness or the proponents of any type of managerial discourse seek to affect a person's worldview or even a person's life by persuading their subjects

\footnotetext{
${ }^{5}$ Also a book under the same title by Joyce Meyer (Hodder \& Stoughton, London, 2012). There is a huge literature on influencing people through language for managerial purposes; e.g., Sarah Myers McGinty, Power Talk: Using Language to Build Authority and Influence, Warner Books, New York, 2001; Murray Kevin, Language of Leaders: How Top CEOs Communicate to Inspire, Influence and Achieve Results, Kogan Page, London, 2012; Egnal Bart, Leading Through Language: Choosing Words That Influence and Inspire, Wiley, Hoboken, NJ, 2015.
} 
to adopt new linguistic habits, this is because they are convinced that a "mode of thought" is already ingrained in language. This is also the case with the mediatic texts in category (LR9). These texts seek traits of a person's or a people's mentality or character in the language they use. Here are some representative examples: "The hidden ways your language betrays your character" (lead: "Every time we open our mouths, we unwittingly reveal our personalities", by Christian Jarrett, $B B C$ July 21, 2017); "People with depression use language differently - Here's how to spot it", The Conversation Apr. 15, 2018). The personality trait can be deduced on the basis of phonological markers alone: "How DEEP is your love? Husky voices signal 'sexual interest' and can help women stand out from the crowd, research suggests" (by Colin Fernandez, The Daily Mail Dec. 19, 2018).

But the indexicality discussed in these texts does not point exclusively to character or personality traits. Compare these thematically different examples (and keep in mind that, as already pointed out, the examples range from the serious to the dubious): "How language problems bedevil the response to crises", an article on telling the story of a gang rape (The Economist Nov. 15, 2018); “Fetal heartbeat' vs. 'forced pregnancy': The language wars of the abortion debate", a recent article on abortion which could also be placed in category (LR7) above (by Amy Harmon, The New York Times May 22, 2019; the article was not in our original corpus); "We need a new language to talk about the economy" (by Tom Clark, The Guardian Feb. 19, 2016), an article reminiscent of the studies in "Whorfian economics" in category (LR2); "How the rise of veganism may tenderise fictional language", an article, which could also appear in category (LRI I), on food metaphors (by Shareena Z. Hamzah, The Conversation Nov. 22, 2018); "Study by women's underwear brand [X] reveals the words women hate the most” (Cision July 30, 2015); or consider this widely circulated meme, of whose origin I am uncertain, ${ }^{6}$ which seems to imply that women are familiar with more color names than men because, one assumes by invoking the relevant stereotype, women are more "fashion-minded" than men:

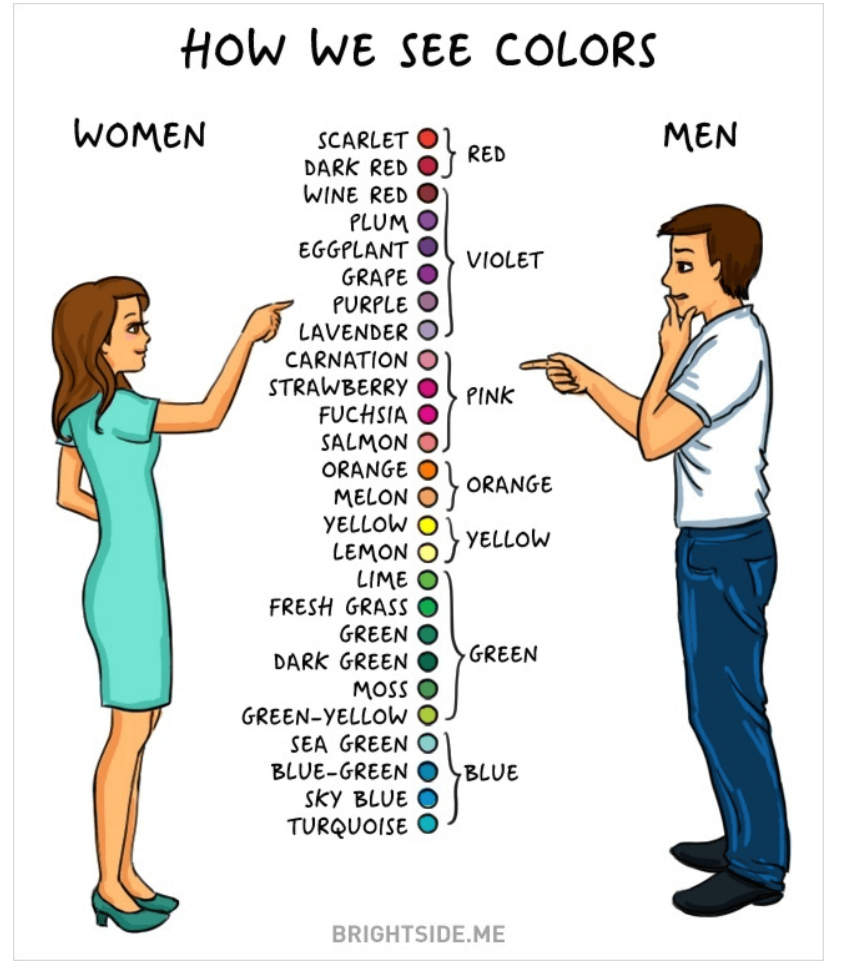

Even Pinker, who, as we saw, is hostile to the very idea of LR, seems to accept some kind of inverse determinism: "Harvard's Steven Pinker: How we speak reveals what we think" (Big Think Apr. 2, 2015).

\footnotetext{
${ }^{6} \mathrm{Cf}$. "When it comes to color, men \& women aren't seeing eye to eye" (by Jordan Gaines Lewis, PhD, Psychology Today Apr. 8, 2015), an article that could also be placed in category (LR2) above.

${ }^{7}$ A more appropriate title for this talk could be: "How we speak reveals how we think". Interestingly enough, the argument
} 
(LRIO). Ideological discourse. 'The language of $\mathrm{X}$ ' is a very common metonymic ("the language of media") or analogical ("the language of art") construction. When X happens to be an ideology, political or other, 'the language of $\mathrm{X}$ ' refers, through inverse determinism, to that ideology's thought patterns (or values or "ideologemes") indexed in the discourse. Here are two examples of this type: "The language of the left" (by Joseph Carli, AIMN Dec. 1, 2018); “The language of neoliberalism” (by Jason Hirthler, Counterpunch Oct. 25, 2013). The language-constraints-thought pattern is also evident in other publications in this category: "How language changes views of the Israeli-Palestinian conflict over Gaza" (by Randa Abdel-Fattah, The Sunday Morning Herald July 18, 2014); "Linguistics can help conservatives and liberals agree on objective reality again” (by Tom Syverson, 2uartz Feb. 23, 2017). ${ }^{8}$

(LRI I). Conceptual metaphors. 'Conceptual metaphors' (Lakoff \& Johnson, 1980), or more generally 'conceptualizations', are precisely what are revealed by the analysis of ideologies, of values, frames of mind or thought patterns. Hence, categories (LRIO) and (LRII) are closely related. Here are a few examples: "Metaphors can change our opinions in ways we don't even realize" (by Steve Rathje, Quartz Mar. 31, 2018); "Declare war on misleading metaphors" (by H.J., The Economist July 21, 2016, in which the warmetaphor is employed for the declared war on the war-metaphor); "6 hidden biases in everyday words (you never noticed before)" (by Michael Dawson, Mike Bedard \& Dan Hopper, Cracked Nov. 21, 2017). Some of these publications refer to the famous analysis of "illness as metaphor" that became a trend after Sontag $(1978,1989)$.

In categories (LRI) - (LR6) we have placed mediatic texts that report on how "language constraints thought". In categories (LR7)-(LRI I) we gave examples of publications that concentrate on how "language indexes thought" through inverse determinism. The next two categories are about different kinds of language affecting thought: new media genres in the case of (LRI2) and older phases of a language in the case of (LRI3).

(LRI 2). Media-genre relativism. Moschonas (2001) has demonstrated that the Greek print media of the period 1999-2001 often portray computer-mediated communication in a negative light with the aim of creating a moral panic about the imminent threat to the Greek language presumably posited by the new media; Thurlow (2006) reaches a similar conclusion having examined English-language news articles of the period 2001-2005; he also finds that the negative evaluation of new media genres "dovetail[s] with a rising concern about the "communicative ineptitude of young people". In the corpus compiled for this study, I have only considered mediatic texts that report on some effect of new media texts, not necessarily a negative one. This is an example of a general expository essay in this category of publications: "How media changes the way we communicate" (Forbes Nov. 7,2017). And this is an example of an article focusing on texting: "The way we text says a lot about our personality" (by Ashley Carman, The Verge Nov. 9, 2018; this text could also be placed under (LR9) above). Although quite a few technophobic texts belong in

that Pinker raises against LR is that it identifies language with thought: "no one believes that language is the same thing as thought and that all of our mental life consists of reciting sentences"; cf. Pinker (1994, p. $57 \mathrm{ff}$.), where he argues that "the idea that thought is the same thing as language is [...] a conventional absurdity". But noone has ever claimed that language and thought are the same thing; to the contrary, in order for language and thought to be correlated, as in "the Sapir-Whorf hypothesis", it is a prerequisite that they be kept apart.

${ }^{8}$ The relativistic assumption that ideologies are somehow ingrained or embedded in language is quite widespread in academic circles as well. Ideology is often presented as an "implicit philosophy" in the practical activities of everyday life (a "philosophy of praxis", according to Gramsci). Some critical discourse analysts employ precisely this metaphor, i.e. that ideology is "embedded" in language; e.g., Fairclough (2001, p. 2, 14) considers ideology to be "pervasively present in language" and speaks of the "ideological properties" of language. The idea that an ideology is ingrained in language itself should not be confused with the idea that an ideology is necessarily implicit, tacit, or presuppositional; cf. Mertz (1982, p. 4) with respect to LR: "Folk theories are tacit; the implicational chain [...] which unites them is not explicitly formulated. Folk theories also contain a kind of internal logic [...]. However, this does not mean that folk theories are necessarily logically consistent". 
this category, my impression is that new media genres are not portrayed anymore in the negative light of the turn of the century. The public debate on whether "Computer coding could fill foreign language requirement in Florida schools" (WFLA Feb. 12, 2016) demonstrates that, for some educators at least, a computer language can be a substitute for a natural one-a metonymic/analogical thinking also evidenced in the mediatic texts of category (LRII).

(LRI 3). Etymological relativism. This category was meant to include mainly those texts that commit the so-called etymological fallacy, i.e. hold that the "real" meaning of a word or phrase can only be understood by grasping the meaning of its etymon; see, e.g., "The etymology of 'orange': Which came first, the color or the fruit?” by Jason Kottke, Kottke.org Aug. 02, 2018). I am not sure whether this is a well-formed category, as it seems to contradict the historical relativism often associated with Boasian anthropology; but see "Can ideas withstand shifts in language? Considering the Sapir-Whorf hypothesis for translation, emoji, and pop culture" (by Elisa Gabbert, Guernica Mar. 11, 2016), which touches on issues that also belong to the category (LRI 2).

Now that we approach the end, we have to move at a quicker pace through the remaining categories.

(LRI4). Cultural relativism. I have established this as a separate category in order to differentiate cultural relativism from LR. Cultural relativism is often propounded as an alternative to linguistic relativity (e.g., by Deutscher, 2010). I take cultural relativism to be the idea that languages "reflect" culture rather than "embody" thought patterns. The mechanics of cultural relativism and of LR are, of course, the same: inverse determinism and indexicality. In languages one supposedly finds the "imprints" of culture or the "traces" of thought habits. However, the interconnected ideas that language "reflects" culture, that culture is "filtered" through a language's "prism", that a language is a "path" or a "window" to another culture, that in languages is preserved the spirit of a people, etc., are more readily associated with cultural relativism. ${ }^{9}$

There is a considerable overlap between the mediatic texts in this category and the ones in (LR4). Here are a few examples: "Cultural sensitivity and the value of learning a language" (by Amelia Rose, The Argus Oct. 31, 2018); "Language and Culture" (by Karen Sternheimer, Everyday Sociology Blog Oct. 8, 2018). Both texts cited are about learning foreign languages. The next one is about a more specific cultural trait: "How do we smell? Terrible! Food sources might affect how we describe scent" (by Nicola Davis, The Guardian Jan. 18, 2018).

For the related categories (LRI 5) and (LRI 6), which require a separate and much longer essay, I will have to refer the reader to previous work (Moschonas, 2001; 2004; 2009).

(LRI 5). Nationalism. The articles in (LR I 5 ) exhibit what is often called "Herderian relativism", a variety much stronger than Whorfian relativism. Herderian relativism is associated with nationalism. It can be analyzed into two major conceptions: that "each language has or is a particular spirit" and that "each language has or is a-real or imagined - territory." This territorial conception of language has been shown to guide the publications in the Greek press about various linguistic issues over a long period of time (Moschonas, 2004). The territorial conception is not so common in England or in the United States, I would think, but it seems to be dominant in communities with linguistic conflicts. Interestingly enough, in both articles cited below, nationalism follows as a corollary from relativism.

Here is an opinion article from The Hindu, which I have chosen because of the overt relativistic tenor

\footnotetext{
${ }^{9}$ Cultural relativism is often interpreted as an ethics of communication. For McWhorter (2014, p. 45), "the dominant impulse of popular Whorfianism is to show ways in which other groups are Westerners' superiors: more aware of kinds of knowing, less caught up in obsessing about the future, more aware of their topography, more sensitive to sources of information". "Popular Whorfian enthusiasm", according to McWhorter (2014, p. 53), "is rooted in what could be termed a religious impulse as well, that is, the modern thinking person's allegiance to valuing, fostering, and defending diversity rather than disparaging it". The moral profile of "popular Whorfianists" that McWhorter draws, is more applicable, I think, to cultural relativists.
} 
of its title: "Language does not simply mirror our world. Language makes it" (by Mini Krishnan, The Hindu June 23, 2018): the article argues for the necessity to teach in schools one more regional language in order to counterbalance the influence of English.

The second example I am going to cite is a post from a Greek blog. The author discusses, among other things, the color vocabulary of various languages in order to show how closely associated is language with thought. He propounds the view that our reality is made up by language. He concludes with the following non sequitur:

People who do not count themselves among an ethnic group, who do not recognize the national and linguistic continuity, they remain rootless, refugees for ever, wherever they find themselves.

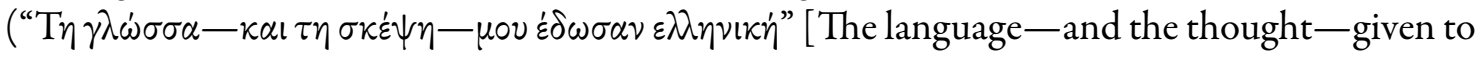
me were Greek], Sanejoker Dec. 26, 2015).

(LRI 6). Prescriptivism. Prescriptivism, especially of the puristic variety, is sustained through nationalism. Here I will cite just one example of reporting on the Académie française banning the so-called "l'écriture inclusive" (gender-neutral expressions), the use of which became a major issue in the French newspapers towards the end of 2017: 'Inclusivity putting French language in 'mortal danger', claims l'Académie française” (by Thomas Godard and Olivia Walsh, The Conversation Nov. 15, 2017).

(LRI7). Talking to Aliens. In 2016, the science fiction film "Arrival" caused a surge of publications in the print and electronic media. The film, based on Ted Chiang's "Story of your life", is about a linguist who is recruited by the military to decipher an alien language. The linguist employs fieldwork techniques and manages to decipher their language by first deciphering their way of thinking; hence, the linguistic relativity. Jessica Coon was the linguistics consultant for the film. She lists several of the publications about the film and the significance of LR for the plot here: "Arrival: Linguistic fieldwork on the big screen"; cf. Moschonas (2017). If nothing else, the case of "Arrival" shows how blurred the distinction is between folk and professional linguistics.

(LRI 8). References en passant. Very often in aesthetic appraisals, e.g. in book or art reviews, there are en passant references to LR. Category (LR I 8) can also be used to cover all those references to LR that are not accounted for by the previous categories. One would think that such references are of minor significance. But the opposite might very well be true. If we had a precise measure of en passant references, then we could reasonably estimate how widespread, commonsensical or presuppositional an idea has become so as to keep appearing where it is less expected.

I will close my presentation of the categories (and of en passant and unacknowledged references to LR) with an excerpt from Kate Tempest's "My Shakespeare". The poem (better seen performed than read) is about how presuppositional Shakespeare's way with words has become; it is about an author becoming a language; it is about LR.

his words are the setting for our stories-he has become a poet whose poetics have embedded themselves deep within the fabric of our language, he's in our mouths, his words have tangled round our own and given rise to expressions so effective in expressing how we feel, we can't imagine how we'd feel without them. 


\section{Summary and a conclusion}

The popularization of LR is a process that started with Benjamin Lee Whorf himself. This was phase 1 in the popularization of LR. Phase 2 continued with the formulation and the testing of LR as a research hypothesis, the "Sapir-Whorf hypothesis", and its consolidation into two principles, the principle of determinism and the principle of relativity proper. The present paper has concentrated on the third, current phase of the popularization of LR. Due to the new media, popularization is now possible on a mass scale.

In order to detect how LR is conceived and talked about in popular discourse, we examined a corpus of metalinguistic texts which either are explicitly about LR or display, without acknowledging it, some characteristic of LR. All texts are available on the internet, although the source for many of them is in the print media.

We divided the mediatic texts into 18 categories, (LRI)-(LRI 8). Expository essays (LRI) and presentations of case studies (LR2) are explicitly about LR. The rest of the categories contain texts that report or opinionate on various linguistic issues under the perspective of LR, without necessarily acknowledging it. Some of the categories-(LR3) on bi-/multi-lingualism, (LR4) on threatened languages, (LR5) on translation, and (LR6) on untranslatable words-are better thought of as loci, as topoi on which notions of LR sprout. The very existence of such loci demonstrates that LR is the principal means for the conceptualization of the relevant topics. Categories (LR7) on political correctness, (LR8) on managerial discourse, (LR9) on inverse determinism and indexicality, (LR IO) on ideological discourse and (LR I I) on conceptual metaphors form a coherent group of publications about the mechanics of LR. LR is presented either as a communicative practice-(LR7) and (LR8) - that has effects on the receiver's attitudes or mode of thought, or, through inverse determinism, as a crystallized linguistic pattern (Whorf would have used the term "fashion of speaking") which indexes the attitudes or the mode of thought of the sender-(LR9) through (LRI I). In the next two categories, the mediatic texts comment on linguistic patterns that are relativized with respect to new media genres (LRI2) and also with respect to the historical meanings of the established linguistic patterns ( $L R \mathrm{I}_{3}$ ). Another group of publications has to do with cultural relativism (LRI4), nationalism (LRIS), and prescriptivism (LRI6)-admittedly this group was not given the attention it deserves in the present study. (LR I 7), communicating with aliens, is an orphan category; but it could be a subcategory of (LR2), another case study, depending on the faith one has in Xenolinguistics or on whether an imaginary, unencountered language could be treated as just another language.

The mediatic texts we have considered (publications in the press and digital media) offer us a "view from half-way high" to LR. LR is indeed a point of contact between professional and folk ideologies about language. We could not understand the real strength of LR if we had limited ourselves within the field of linguistics. We have not disregarded how misinformed, uninformative, or even silly mass media accounts of LR often are. But we also have not overlooked the fact that, in the case of LR, mass media discourse has its origins in academic discourse.

The categories under which we have examined LR in popularized and/or popularizing discourse do not coincide-or they coincide only in part—with what Lee (1996) calls "the Whorf theory complex" consisting of twelve "elements" or parts; they do not coincide—or coincide only in part—with Silverstein's (2000, p. 98-101) seven-part reconstruction of how cultural concepts emerge in language according to Whorf. And certainly do not coincide with the hasty sketches of popular Whorfianism found in the virulent works of such writers as McWhorter, Deutscher, or Pinker. This has been our predicament: in order to come to recognize LR's presuppositions we have taken as a frame of reference the secondary academic literature on LR, with the danger that presuppositions embodied in LR "from outside" have escaped us; but it is precisely those influences that come "from outside" that have contributed to LR's transformation into a common ideology, a "popular movement"-or a widespread disease. Indeed, in the categories that form the middle group (LR7)-(LRI I), LR seems to be the unacknowledged but dominant ideology (in the sense of Abercrombie \& Turner, 1978), both within and outside the academia. It is now 
the default ideology for issues of (critical) analysis of texts.

Linguistic relativity is a view into what is different. It provides a lens through which one looks at aspects of language one is not familiar with. For this reason, popularizing linguistic relativity is simply another means of calibration, additional to translation, glossing, ${ }^{10}$ or strict linguistic exegesis. Let us remind ourselves of what Whorf (1956, p. 214) says about LR and calibration:

no individual is free to describe nature with absolute impartiality but is constrained to certain modes of interpretation even while he thinks himself most free. The person most nearly free in such respects would be a linguist familiar with very many widely different linguistic systems. As yet no linguist is in any such position. We are thus introduced to a new principle of relativity, which holds that all observers are not led by the same physical evidence to the same picture of the universe, unless their linguistic backgrounds are similar, or can in some way be calibrated.

This rather startling conclusion is not so apparent if we compare only our modern European languages, with perhaps Latin and Greek thrown in for good measure. Among these tongues there is a unanimity of major pattern which at first seems to bear out natural logic. But this unanimity exists only because these tongues are all Indo-European dialects cut to the same basic plan, being historically transmitted from what was long ago one speech community; because the modem dialects have long shared in building up a common culture; and because much of this culture, on the more intellectual side, is derived from the linguistic backgrounds of Latin and Greek. Thus this group of languages satisfies the special case of the clause beginning "unless" in the statement of the linguistic relativity principle at the end of the preceding paragraph. From this condition follows the unanimity of description of the world in the community of modern scientists. But it must be emphasized that "all modern Indo-European-speaking observers" is not the same thing as "all observers".

Notice, first, that for Whorf LR is a principle, not a hypothesis. Notice also that LR is about observations; hence, it is a metalinguistic principle. In addition to translation and other translation-related means of calibration, talking about languages, explicating their structure, bringing forth their hidden, cryptic logic, even talking about linguistic relativity and about calibration, all these are also means of calibration. Linguistic relativity aims at language awareness. ${ }^{11}$ And this is perhaps what popular discourse about or informed by linguistic relativity should strive to achieve.

As a metalinguistic principle, the linguistic relativity itself is a means of calibrating languages; and so is popularizing linguistic relativity.

\section{Bibliography}

Abercrombie, N. \& Turner, B.S. (1978). The Dominant Ideology Thesis, in “The British Journal of Sociology", 29 (2), p. 149170 , Crossref.

Antoniou, M. (2019). The advantages of bilingualism debate, in “Annual Review of Linguistics", 5, p. 395-415, Crossref.

Athanasopoulos, P., Bylund, E. \& Montero-Melis, G. (2015). Two languages, two minds: Flexible cognitive processing driven by language of operation, in "Psychological Science", 26 (4), p. 518-526, Crossref.

Baker, A.E. \& Hengeveld, K. (eds) (2012). Linguistics, Wiley-Blackwell, Hoboken, NJ.

Benveniste, É. (1939). Nature du signe linguistique, in "Acta Linguistica", 1 (1), p. 23-29, Crossref.

Bereby-Meyer, Y., Hayakawa, S., Shalvi, Sh., Corey, J.D., Costa, A. \& Keysar, B. (2018). Honesty speaks a second language, in "Topics in Cognitive Science", 12 (2), p. 632-643, Crossref.

Berlin, B. \& Kay, P. (1999). Basic Color Terms: Their Universality and Evolution, CSLI Standford ( $1^{\text {st }}$ ed.: 1991).

Björk, I. (2008). Relativizing Linguistic Relativity: Investigating Underlying Assumptions About Language in the Neo-Whorfian Literature, PhD thesis, Uppsala Universitet, Uppsala, [online].

\footnotetext{
${ }^{10}$ On Whorf's intricate "mechanism of glossing” see Silverstein (2000, p. 92 ff., 131 n. 10).

${ }^{11}$ Lee (1996, p. 224-225) stresses that Whorfian Metalinguistics is "the intercalibration of agreement through language awareness".
} 
Bock, Ph.K. (2003). World view and language, in Frawley, W. (ed.), International Encyclopedia of Linguistics, $2^{\text {nd }}$ ed., vol. 4 , p. 463-466, Oxford University Press, Oxford ( $1^{\text {st }}$ ed.: 1992).

Boroditsky, L. (2003). Linguistic Relativity, in Nadel, L. (ed.), Encyclopedia of Cognitive Science, vol. 2, p. 917-921, Nature Publishing Group, London, Crossref.

Brown, R. \& Lenneberg, E. H. (1954). A Study in Language and Cognition, in Psycholinguistics: Selected Papers by Roger Brown, p. 235-273, The Free Press, New York, 1970.

Brown, R. (1958). Words and Things: An Introduction to Language, The Free Press, New York.

Carroll, J. B. (1953). The Study of Language: A Survey of Linguistics and Related Disciplines in America, Harvard University Press, Cambridge, MA.

Cassin, B. (ed.) (2004). Dictionary of Untranslatables: A Philosophical Lexicon, translated by S. Rendall et al., Princeton University Press, Princeton.

Costa, A. (2019). The Bilingual Brain and What it Tells Us About the Science of Language, Penguin Books, London.

Darnell, R. (2001). Invisible Genealogies: A History of Americanist Anthropology, University of Nebraska Press, Lincoln / London.

Darnell, R. (2006). Benjamin Lee Whorf and the Boasian foundations of contemporary ethnolinguistics, in Jourdan, Ch. \& Tuite, K. (eds), Language, Culture, and Society: Key Topics in Linguistic Anthropology, p. 82-95, Cambridge University Press, Cambridge, Crossref.

Deutscher, G. (2010). Through the Language Glass: Why the World Looks Different in Other Languages, Henry Holt, New York.

Elffers, E. (1996). The history of thought about language and thought, in Cremers, C. \& den Dikken, M. (eds), Linguistics in the Netherlands 1996, p. 73-84, John Benjamins, Amsterdam / Philadelphia, Crossref.

Everett, C. (2013). Linguistic Relativity: Evidence Across Languages and Cognitive Domains, de Gruyter, Berlin, Crossref.

Everett, D. (2008). Don't Sleep, There are Snakes: Life and Language in the Amazonian Jungle, Profile Books, London.

Fairclough, N. (2001). Language and Power, $2^{\text {nd }}$ ed., Longman, London.

Franklin A., Drivonikou, G. V., Bevis, L., Davies, I. R.L., Kay, P. \& Regier, T. (2008). Categorical perception of color is lateralized to the right hemisphere in infants, but to the left hemisphere in adults, in "Proceedings of the National Academy of Sciences", 105 (9), p. 3221-3225, Crossref.

Fromkin, V., Rodman, R. \& Hyams, N. (2011). An Introduction to Language, $9^{\text {th }}$ ed., Wadsworth, Belmont, CA.

Gumperz, J.J. \& Levinson, S. C. (eds) (1996). Rethinking Linguistic Relativity, Cambridge University Press, Cambridge.

Hernandez, A.E. (2013). The Bilingual Brain, Oxford University Press, Oxford.

Hill, J.H. \& Mannheim, B. (1992). Language and world view, in "Annual Review of Anthropology”, 21, p. 381-404, Crossref.

Hoijer, H. (1954). The Sapir-Whorf hypothesis, in Hoijer, H. (ed.), Language in Culture: Conference on the Interrelations of Language and Other Aspects of Culture, p. 92-105, University of Chicago Press, Chicago.

Javier, R.A. (2007). The Bilingual Mind: Thinking, Feeling and Speaking in Two Languages, Springer, New York, Crossref.

Joseph, J.E. (1996). The immediate sources of the 'Sapir-Whorf Hypothesis', in "Historiographia Linguistica”, 23 (3), p. 365-404, Crossref.

Koerner, E. F.K. (1992). The Sapir-Whorf Hypothesis: A preliminary history and a bibliographical essay, in "Journal of Linguistic Anthropology", 2 (2), p. 173-198, Crossref.

Koerner, E. F.K. (2000). Towards a 'full pedigree' of the 'Sapir-Whorf Hypothesis': From Locke to Lucy, in Pütz. M. \& Verspoor, M.H. (eds), Explorations in Linguistic Relativity, p. 1-23, John Benjamins, Amsterdam/Philadelphia, Crossref.

Koerner, E. F. K. (2002). Toward a History of American Linguistics, Routledge, London.

Labov, W. (1982). Objectivity and commitment in linguistic science: The case of the Black English Trial in Ann Arbor, in "Language in Society", 11 (2), p. 165-201, Crossref.

Lakoff, G. \& Johnson, M. (1980). Metaphors We Live By, The University of Chicago Press, Chicago/London.

Langus, A., Seyed-Allaei, S., Uysal E., Pirmoradian, S., et al. (2016). Listening natively across perceptual domains? in "Journal of Experimental Psychology: Learning, Memory, and Cognition", 42 (7), p. 1127-1139, Crossref.

Leavitt, J. (2011). Linguistic Relativities: Language Diversity and Modern Thought, Cambridge University Press, Cambridge, Crossref.

Lee, P. (1996). The Whorf Theory Complex: A Critical Reconstruction, John Benjamins, Amsterdam/Philadelphia, Crossref.

Levinson, S. C. (2003). Space in Language and Congition: Explorations in Cognitive Diversity, Cambridge University Press, Cambridge, Crossref.

Lucy, J.A. (1992a). Language Diversity and Thought: A Reformulation of the Linguistic Relativity Hypothesis, Cambridge University Press, Cambridge, Crossref.

Lucy, J.A. (1992b). Grammatical Categories and Cognition: A Case Study of the Linguistic Relativity Hypothesis, Cambridge University Press, Cambridge, Crossref.

Lyons, J. (1981). Language and Linguistics: An Introduction, Cambridge University Press, Cambridge, Crossref.

Maier, M. \& Rahman, R.A. (2018). Native language promotes access to visual consciousness, in "Psychological Science", 29 (11), p. 1757-1772, Crossref.

McWhorter, J.H. (2014). The Language Hoax: Why the World Looks the Same in Any Language, Oxford University Press, 
Oxford.

Mertz, E. (1982). Language and mind: A whorfian folk theory in United States language law, Sociolinguistics Working Paper 93, Southwest Educational Development Laboratory, Austin, TX.

Mertz, E. \& Parmentier, R.J. (eds) (1985). Semiotic Mediation: Sociocultural and Psychological Perspectives, Academic Press, Orlando, FL.

Miller, R.L. (1968). The Linguistic Relativity Principle and Humboldtian Ethnolinguistics: A History and Appraisal, Mouton, The Hague, Crossref.

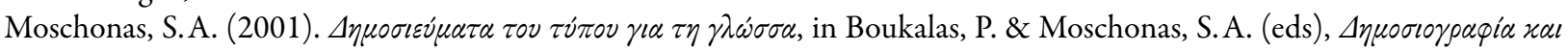

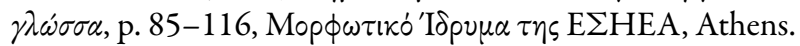

Moschonas, S.A. (2004). Relativism in language ideology: On Greece's latest language issue[s], in "Journal of Modern Greek Studies", 22 (2), p. 173-206, Crossref.

Moschonas, S. A. (2009). "Language issues" after the "language question": On the modern standards of Standard Modern Greek, in Georgakopoulou, A. \& Silk, M. (eds), Standard Languages and Language Standards: Greek, Past and Present, p. 293-320, Ashgate, London.

Moschonas, S.A. (2014). The media on media-induced language change, in Androutsopoulos, J. (ed.), Mediatization and Sociolinguistic Change, p. 395-426, de Gruyter, Berlin, Crossref.

Moschonas, S. A. (2017). H $\alpha \gamma \dot{\alpha} \pi \eta \tau \omega \nu \nu \varepsilon x \rho \omega \dot{\nu}$, in “The Athens Review of Books”, 80, p. 60-62.

Niemeier, S. \& Dirven, R. (eds) (2000). Evidence for Linguistic Relativity, John Benjamins, Amsterdam/Philadelphia, Crossref.

Pavlenko, A. (2014). The Bilingual Mind and What it Tells Us About Language and Thought, Cambridge University Press, Cambridge, Crossref.

Penn, J.M. (1992). Linguistic Relativity Versus Innate Ideas: The Origin of the Sapir-Whorf Hypothesis in German Thought, Mouton, The Hague, Crossref.

Pinker, S. (1994). The Language Instinct: How The Mind Creates Language, William Morrow, New York.

Pinker, S. (2007). The Stuff of Thought: Language as a Window into Human Nature, Penguin Books, London.

Pullum, G. K. (1991). The Great Eskimo Vocabulary Hoax and Other Irreverent Essays on the Study of Language, The University of Chicago Press, Chicago.

Pütz. M. \& Verspoor, N.H. (eds) (2000). Explorations in Linguistic Relativity, John Benjamins, Amsterdam/Philadelphia, Crossref.

Saussure, F. de (1995). Cours de linguistique générale, Payot, Paris (1 $1^{\text {st }}$ ed.: 1916).

Sassure, F. de (2006). Writings in General Linguistics, translated by M. Pires \& C. Sanders, Oxford University Press, Oxford (French. ed.: 2002).

Schultz, E. A. (1990). Dialogue at the Margins: Whorf, Bakhtin, and Linguistic Relativity, The University of Wisconsin Press, Madison, WI.

Silverstein, M. (1985). Language and the culture of gender: At the intersection of structure, usage, and ideology, in Mertz, E. \& Parmentier, R.J. (eds), Semiotic Mediation: Sociocultural and Psychological Perspectives, p. 219-259, Academic Press, Orlando, FL, Crossref.

Silverstein, M. (2000). Whorfianism and the linguistic imagination of nationality, in Kroskrity, P. V. (ed.), Regimes of Language: Ideologies, Polities, and Identities, p. 85-138, School of American Research Press, Santa Fe, NM. / James Currey, Oxford.

Sontag, S. (1978). Illness as Metaphor, Farrar, Straus \& Giroux, New York.

Sontag, S. (1989). AIDS and its Metaphors, Farrar, Straus \& Giroux, New York.

Spitzmüller, J. \& Warnke, I.H. (2011). Diskurs-Linguistik: Eine Einführung in Theorien und Methoden der transtextuellen Sprachanalyse, de Gruyter, Berlin, Crossref.

Spitzmüller, J. (2005). Metasprachdiskurse: Engstellungen zu Anglizismen und ibre wissenschaftliche Rezeption, de Gruyter, Berlin, Crossref.

Stam, J.H. (1980). An historical perspective on 'linguistic relativity', in Rieber, R. W. (ed.), Psychology of Language and Thought: Essays on the Theory and History of Psycholinguistics, p. 239-262, Plenum Press, New York.

Suchotzki, K. \& Gamer, M. (2018). The language of lies: Behavioral and autonomic costs of lying in a native compared to a foreign language, in "Journal of Experimental Psychology: General", 147 (5), p. 734-746, Crossref.

Thurlow, C. (2006). From statistical panic to moral panic: The metadiscursive construction and popular exaggeration of new media language in the print media, in "Journal of Computer Mediated Communication", 11 (3), p. 667-701, Crossref.

Whorf, B. L. (1956). Language,Thought, and Reality: Selected Writings of Benjamin Lee Whorf, ed. by J. B. Carroll, The M.I.T. Press, Cambridge, Mass. 